\title{
A comparative study of acrylate oligomer on jatropha and palm oil-based UV-curable surface coating
}

\begin{abstract}
We report a novel family of acrylate-functional monomers/oligomers derived from epoxidized jatropha oil using acrylic acid. Acrylated epoxy jatropha oil-based polymer was synthesized in two steps reaction. Oligomers were coated on glass substrate and cross-linked afterwards by UV irradiation. The coating properties such as gloss, scratch hardness and chemical resistance were evaluated via standard methods. A comparative study of jatropha and palm oil based acrylate UV coatings was conducted. The most important and economic method for the acrylation of epoxidized jatropha oil requires a 6-h reaction time compared to palm oil that requires a 20 -h reaction time. The acrylated epoxidized jatropha oil exhibited improved glossiness, UV curing time and hardness over the acrylated epoxidized palm oil.
\end{abstract}

Keyword: Acrylated epoxy jatropha oil; UV curing; Surface coating; Acrylate oligomer 